\title{
Update on host-pathogen interactions in cystic fibrosis lung disease
}

\author{
Andreas Hector, Nina Frey and Dominik Hartl ${ }^{*}$
}

\begin{abstract}
Bacterial and fungal infections are hallmarks of cystic fibrosis (CF) lung disease. In the era of long-term inhaled antibiotics and increasing CF patient survival, new "emerging" pathogens are detected in CF airways, yet their pathophysiological disease relevance remains largely controversial and incompletely defined. As a response to chronic microbial triggers, innate immune cells, particularly neutrophils, are continuously recruited into CF airways where they combat pathogens but also cause tissue injury through release of oxidants and proteases. The coordinated interplay between host immune cell activation and pathogens is essential for the outcome of CF lung disease. Here, we provide a concise overview and update on host-pathogen interactions in CF lung disease.
\end{abstract}

\section{Manuscript}

\section{CF lung disease}

Lung disease determines the morbidity and mortality of patients with cystic fibrosis (CF), a lethal monogenetic disease caused by mutations in the cystic fibrosis transmembrane conductance regulator (CFTR) gene [21]. Hallmarks of CF lung disease are its chronic, nonresolving and perpetuating nature. Importantly, a key characteristic of CF lung disease is the early and maintained interplay of microbial infection and severe airway inflammation [16]. The altered CF lung environment, characterized by mucus obstruction, airway surface liquid dehydration, $\mathrm{pH}$ dysregulation (lower, acidic $\mathrm{pH}$ ), and high burden of extracellular proteases (mainly neutrophil elastase and matrix metalloproteases) favors microbial airway colonization and abnormal/inefficient host immunity $[16,21]$. While inflammation in general is essential and indispensable to clear microbial infections and restore tissue integrity and homeostasis in acute infective conditions such as bacterial pneumonia, the pro-inflammatory response mechanisms activated in CF lung disease seem to be acting in an excessive, nonbalanced, and therefore perpetuated manner [6]. The resulting immune cell infiltration leads to irreversible tissue remodeling with bronchiectasis and loss of lung function. Overall, host-pathogen interactions in CF are complex since they (1) depend on the individual CFTR

\footnotetext{
* Correspondence: Dominik.hartl@med.uni-tuebingen.de Department of Pediatrics I, University of Tübingen, Tübingen, Germany
}

mutation class, (2) evolve mutually in a temporal and spatial manner, and (3) are regulated by bacterial and fungal phenotypes, such as biofilm formations [17, 28, 35]. Here, we aim to provide a concise overview on host-pathogen interactions in CF lung disease in order to shed light on new avenues for future research and treatment approaches.

\section{Microbial airway colonization in CF lung disease}

$\mathrm{CF}$ airways are mainly colonized by specific bacteria and fungi [28]. Among bacteria, Pseudomonas aeruginosa and Staphylococcus aureus are the most abundant and consequently most thoroughly studied pathogens. In early infancy, CF airways are typically colonized with $S$. aureus and Haemophilus influenzae. Later on in childhood, $P$. aeruginosa predominates and modulates disease outcome substantially [3]. Upon chronic colonization, $P$. aeruginosa can adapt this phenotype by conversion into a mucoid form that is more resistant to antibiotics and host defense. The majority of inhaled or systemic antibiotics used to treat CF patients is actually directed against $P$. aeruginosa in order to eradicate or suppress this opportunistic Gram-negative bacterium [7]. The underlying host-pathogen interaction mechanisms regulating the CF-characteristic microbial "switch" from S. aureus and $H$. influenzae to $P$. aeruginosa remain, however, controversial and incompletely understood, but probably involve pathogen-derived factors, such as pyocyanin and host-derived immune factors as well as environmental influences. In the era of commonly and early used
Springer

(C) 2016 Hector et al. Open Access This article is distributed under the terms of the Creative Commons Attribution 4.0 International License (http://creativecommons.org/licenses/by/4.0/), which permits unrestricted use, distribution, and reproduction in any medium, provided you give appropriate credit to the original author(s) and the source, provide a link to the Creative Commons license, and indicate if changes were made. 
inhaled antibiotics and prolonged patient survival, new "emerging" pathogens are increasingly detected in CF airway fluids, particularly fungi, such as Aspergillus fumigatus [2, 26], Candida albicans [9, 10], and Scedosporium species [22], and the bacteria Stenotrophomonas maltophilia [13], Achromobacter xylosoxidans [12, 15], methicillin-resistant S. aureus (MRSA) [14], Burkholderia cepacia $[11,25]$, and atypical mycobacteria (nontuberculous mycobacteria, NTMs) [1, 23], which are often hard to treat in the clinics due to antibiotic resistance patterns [7, 8, 31, 33, 34]. Whereas the prevalence (or at least the detection rate) of these microbial species increases in most CF centers, their pathophysiological disease relevance for the outcome of $\mathrm{CF}$ lung disease remains controversial and poorly defined. MRSA [14], $B$. cepacia, and NTMs [23] are broadly accepted as harmful CF pathogens, while for other rare species (such as $S$. maltophilia [13, 30, 32]), this is less clear.

\section{Host immunity}

Faced with the presence of bacterial and fungal microbial species, the host immune response reacts by recruiting innate and adaptive immune cells into the infected CF airway compartment. Among innate immune cells, neutrophils are the most rapid and predominant cell type transmigrating into CF airways, while in adaptive immunity, T-helper cell type 2 (Th2) and Th17 cell responses are predominant [16], while regulatory $\mathrm{T}$ cell responses are impaired [18]. Remarkably, phagocytic innate immune cells (neutrophils and macrophages) preferentially accumulate within the airway compartment, whereas, in contrast, lymphocytes are mainly found in lung tissues, but are very low within the airway lumen [24]. The underlying migratory and/or tissue homeostatic mechanisms regulating this distinct immune cell tissue compartment localization/distribution remain to be defined, yet recent studies suggest that neutrophils can suppress and thereby dampen T cell activity at sites of inflammation [19]. When innate immune cells are in physical contact with pathogens, several factors decide which anti-microbial defense mechanisms are employed; phagocytotic uptake is the most rapid and principal effector function against smaller bacteria and fungi, particularly after antibodyand/or complement-mediated opsonisation [20]. If pathogen size exceeds a critical threshold or pathogens shield themselves through biofilms, neutrophils are unable to efficiently phagocytose pathogens and utilize their extracellular host defense armamentarium, consisting of neutrophil extracellular trap (NET) formation [4] and the release of intracellularly stored anti-microbial effector proteins (such as defensins and proteases) [20]. In CF airways in vivo, probably a combination of these host defense mechanisms is operative, yet studies comparing the relative contribution of these distinct neutrophil functionalities to host defense outcome within the CF airways are lacking (to the best of our knowledge). Beyond cellular mechanisms, studies involved a dysregulated ceramide homeostasis/turnover in CF lung disease by showing that ceramide accumulates in CF airways and mediates inflammation, cell death, and infection susceptibility [29].

\section{Conclusion}

Our understanding of host-pathogen interactions in CF lung disease is continuously and substantially renewed by current findings in microbiology (for instance by the microbiome [27]) and immunology/cell biology (for instance by the discovery of NET formation [5]). The challenge for the future remains to combine insights from these two often disconnected scientific fields and to translate them efficiently into the complex pathogenesis of CF lung disease. A more precise dissection/stratification of host-pathogen interaction components into beneficial (anti-infective, host defensive) and harmful (collateral tissue damage) subtypes could pave the way to develop novel optimized strategies for biomarker development and therapeutic drug targeting in CF lung disease.

\section{Authors' contributions}

$\mathrm{AH}$ reviewed the literature and wrote the manuscript. NF co-wrote the manuscript. DH supervised and contributed to the manuscript writing and the related discussions. All authors read and approved the final manuscript

Received: 23 October 2015 Accepted: 16 February 2016

Published online: 23 February 2016

\section{References}

1. Adjemian J, Olivier KN, Prevots DR (2014) Nontuberculous mycobacteria among patients with cystic fibrosis in the United States: screening practices and environmental risk. Am J Respir Crit Care Med 190:581-586

2. Amin R, Dupuis A, Aaron SD et al (2010) The effect of chronic infection with Aspergillus fumigatus on lung function and hospitalization in patients with cystic fibrosis. Chest 137:171-176

3. Bendiak GN, Ratjen F (2009) The approach to Pseudomonas aeruginosa in cystic fibrosis. Semin Respir Crit Care Med 30:587-595

4. Branzk N, Lubojemska A, Hardison SE et al (2014) Neutrophils sense microbe size and selectively release neutrophil extracellular traps in response to large pathogens. Nat Immunol 15:1017-1025

5. Brinkmann V, Zychlinsky A (2007) Beneficial suicide: why neutrophils die to make NETs. Nature reviews. Microbiology 5:577-582

6. Cantin AM, Hartl D, Konstan MW et al (2015) Inflammation in cystic fibrosis lung disease: pathogenesis and therapy. J Cyst Fibros 14:419-430

7. Chmiel JF, Aksamit TR, Chotirmall SH et al (2014) Antibiotic management of lung infections in cystic fibrosis. I. The microbiome, methicillin-resistant Staphylococcus aureus, gram-negative bacteria, and multiple infections. Ann Am Thorac Soc 11:1120-1129

8. Chmiel JF, Aksamit TR, Chotirmall SH et al (2014) Antibiotic management of lung infections in cystic fibrosis. II. Nontuberculous mycobacteria, anaerobic bacteria, and fungi. Ann Am Thorac Soc 11:1298-1306

9. Chotirmall SH, Greene CM, Mcelvaney NG (2010) Candida species in cystic fibrosis: a road less travelled. Med Mycol 48:S114-S124

10. Chotirmall SH, O'donoghue E, Bennett K et al (2010) Sputum Candida albicans presages FEV(1) decline and hospital-treated exacerbations in cystic fibrosis. Chest 138:1186-1195 
11. Courtney JM, Dunbar KE, Mcdowell A et al (2004) Clinical outcome of Burkholderia cepacia complex infection in cystic fibrosis adults. J Cyst Fibros 3:93-98

12. De Baets F, Schelstraete $P$, Van Daele $S$ et al (2007) Achromobacter xylosoxidans in cystic fibrosis: prevalence and clinical relevance. J Cyst Fibros 6:75-78

13. Goss CH, Mayer-Hamblett N, Aitken ML et al (2004) Association between Stenotrophomonas maltophilia and lung function in cystic fibrosis. Thorax 59:955-959

14. Goss CH, Muhlebach MS (2011) Review: Staphylococcus aureus and MRSA in cystic fibrosis. J Cyst Fibros 10:298-306

15. Hansen CR, Pressler T, Nielsen KG et al (2010) Inflammation in Achromobacter xylosoxidans infected cystic fibrosis patients. J Cyst Fibros 9:51-58

16. Hartl D, Gaggar A, Bruscia E et al (2012) Innate immunity in cystic fibrosis lung disease. J Cyst Fibros 11:363-382

17. Hassett DJ, Korfhagen TR, Irvin RT et al (2010) Pseudomonas aeruginosa biofilm infections in cystic fibrosis: insights into pathogenic processes and treatment strategies. Expert Opin Ther Targets 14:117-130

18. Hector A, Schafer H, Poschel S et al (2015) Regulatory $T$ cell impairment in cystic fibrosis patients with chronic pseudomonas infection. Am J Respir Crit Care Med 191(8):914-923

19. Ingersoll SA, Laval J, Forrest OA et al (2015) Mature cystic fibrosis airway neutrophils suppress $T$ cell function: evidence for a role of arginase 1 but not programmed death-ligand 1. J Immunol 194:5520-5528

20. Kruger P, Saffarzadeh M, Weber AN et al (2015) Neutrophils: between host defence, immune modulation, and tissue injury. PLoS Pathog 11, e1004651

21. Mall MA, Hartl D (2014) CFTR: cystic fibrosis and beyond. Eur Respir J 44: 1042-1054

22. Nagano Y, Cherie MB, Goldsmith CE, et al. (2009) Emergence of Scedosporium apiospermum in patients with cystic fibrosis. BMJ Case Reports:bcr2007119503

23. Nick JA (2003) Nontuberculous mycobacteria in cystic fibrosis. Semin Respir Crit Care Med 24:693-702

24. Regamey N, Tsartsali L, Hilliard TN et al (2011) Distinct patterns of inflammation in the airway lumen and bronchial mucosa of children with cystic fibrosis. Thorax 67(2):164-170

25. Regan KH, Bhatt J (2014) Eradication therapy for Burkholderia cepacia complex in people with cystic fibrosis. Cochrane Database Syst Rev 10, CD009876

26. Shoseyov D, Brownlee KG, Conway SP et al (2006) Aspergillus bronchitis in cystic fibrosis. Chest 130:222-226

27. Surette MG (2014) The cystic fibrosis lung microbiome. Ann Am Thorac Soc 11(Suppl 1):S61-S65

28. Tang AC, Turvey SE, Alves MP et al (2014) Current concepts: host-pathogen interactions in cystic fibrosis airways disease. Eur Respir Rev 23:320-332

29. Teichgraber V, Ulrich $M$, Endlich $N$ et al (2008) Ceramide accumulation mediates inflammation, cell death and infection susceptibility in cystic fibrosis. Nat Med 14:382-391

30. Waters V, Atenafu EG, Salazar JG et al (2012) Chronic Stenotrophomonas maltophilia infection and exacerbation outcomes in cystic fibrosis. J Cyst Fibros 11:8-13

31. Waters $V$, Ratjen F (2014) Antibiotic treatment for nontuberculous mycobacteria lung infection in people with cystic fibrosis. Cochrane Database Syst Rev 12, CD010004

32. Waters V, Yau Y, Prasad S et al (2011) Stenotrophomonas maltophilia in cystic fibrosis: serologic response and effect on lung disease. Am J Respir Crit Care Med 183:635-640

33. Waters VJ, Ratjen FA (2014) Is there a role for antimicrobial stewardship in cystic fibrosis? Ann Am Thorac Soc 11:1116-1119

34. Waters VJ, Stanojevic S, Sonneveld N et al (2015) Factors associated with response to treatment of pulmonary exacerbations in cystic fibrosis patients. J Cyst Fibros 14(6):755-762

35. Yonker LM, Cigana C, Hurley BP et al (2015) Host-pathogen interplay in the respiratory environment of cystic fibrosis. J Cyst Fibros 14:431-439

\section{Submit your manuscript to a SpringerOpen ${ }^{\circ}$ journal and benefit from:}

- Convenient online submission

- Rigorous peer review

- Immediate publication on acceptance

- Open access: articles freely available online

- High visibility within the field

- Retaining the copyright to your article

Submit your next manuscript at $>$ springeropen.com 